\title{
Comparison of Fracture Resistance of Primary Incisors Restored with Different Intracanal-Reinforcement Materials
}

\author{
Fouad Salama (D) \\ Faika Abdelmegid ${ }^{2}$ \\ Mohammed Alhussain ${ }^{3}$ \\ Hasan Muaddi ${ }^{3}$ \\ Nassr AIMaflehi $\mathbb{D i D}^{4}$ \\ Latifa Alhowaish (ID) \\ 'Department of Pediatric Dentistry and \\ Orthodontics, College of Dentistry, King \\ Saud University, Riyadh, Saudi Arabia; \\ ${ }^{2}$ Department of Oral Medicine and \\ Diagnostic Sciences, College of Dentistry, \\ King Saud University, Riyadh, Kingdom of \\ Saudi Arabia; ${ }^{3}$ College of Dentistry, King \\ Saud University, Riyadh, Kingdom of \\ Saudi Arabia; ${ }^{4}$ Department of \\ Periodontics and Community Dentistry, \\ College of Dentistry, King Saud \\ University, Riyadh, Kingdom of Saudi \\ Arabia
}

\begin{abstract}
Aim: To evaluate the effects of placing short posts made of different restorative materials on the fracture resistance of root canals in primary incisors of primary teeth.

Materials and Methods: The root canals of 40 extracted primary incisors were prepared and filled with Vitapex and randomly divided into five groups of 8 each. In Groups 1-4, a post space was created and filled with different restorative materials (Tetric ${ }^{\circledR}$ N-Ceram Bulk Fill, AeliteFlo, Filtek Z250 XT, and GC Fuji II LC ${ }^{\circledR}$ capsule), while Group 5 was kept filled with Vitapex as a control. Fracture resistance was measured using a universal testing machine at a $0.5-\mathrm{mm} / \mathrm{min}$ crosshead speed. The results were statistically analyzed and compared.

Results: The highest fracture resistance was recorded for GC Fuji II LC capsules [439.82 N] and control [423.37 N], while the lowest fracture resistance was recorded for Tetric ${ }^{\circledR} \mathrm{N}$ Ceram Bulk Fill $(239.91 \mathrm{~N})$. A multiple comparison test showed that the Tetric ${ }^{\circledR}$ N-Ceram Bulk Fill had a significantly lower average value than AeliteFlo $(\mathrm{P}=0.030)$, as well as a significantly lower average value than GC Fuji II LC ${ }^{\circledR}$ capsule $(\mathrm{P}=0.001)$, and a significantly lower average value than the control group $(\mathrm{P}=0.002)$. Multiple comparison tests showed no significant difference between Tetric ${ }^{\circledR}$ N-Ceram Bulk Fill and Filtek Z250 XT $(P=0.39)$.

Conclusion: The fracture resistance of primary incisor root canals differs according to the material used for the intracanal posts. Three-millimeter intracanal posts in the primary incisors showed the highest fracture resistance for the teeth restored with GC Fuji II LC capsules and the control.
\end{abstract}

Keywords: fracture resistance, intracanal posts, primary incisors, resin composite

\section{Introduction}

It is challenging for pediatric dentists to restore badly broken down teeth. ${ }^{1-3}$ The goal of dental treatment is to restore the lost tooth structure. ${ }^{4}$ Several attempts have been made by clinicians to restore grossly decayed anterior primary teeth with root canal posts including premanufactured orthodontic wire, ${ }^{1,5-7}$ metallic posts with macro-retention, ${ }^{8}$ short posts with composite resin, ${ }^{7,9}$ polyethylene ribbond posts, ${ }^{1}$ composite resin posts with undercut, $^{3,6,10}$ biologic posts, ${ }^{6,11,12}$ glass fiber posts, ${ }^{2,3,7}$ reversed prefabricated metal posts, ${ }^{13}$ and polymers as screw post. ${ }^{14}$ Some reviews listed methods of intracanal reinforcement as well as case reports for severely decayed primary teeth. ${ }^{15-18}$

Post placement in primary teeth is indicated in the following conditions: $2 / 3 \mathrm{rd}$ of tooth structure left, at least $1 \mathrm{~mm}$ of tooth structure supragingival, and reduced crown tooth structure. ${ }^{8,18}$ The main reason for using a post is to provide support for the final restoration and increase the resistance of the restored tooth to mechanical
Correspondence: Latifa Alhowaish

Email lalhowaish@ksu.edu.sa 
load. ${ }^{8,18}$ Problems may arise during placement of posts in primary teeth due to the morphology and histology of primary teeth with less surface area for bonding. Destruction of the tooth structure frequently involves the entire crown, leaving just the root dentin for bonding of the restorative material and thus increasing the failure rate..$^{5,18,19}$

There are no previous clinical studies that compared the effectiveness of bulk-fill resin composites, flowable resin composites, nanohybrid universal resin, and resinmodified glass ionomer posts in restoring simulated badly broken down primary incisors. Therefore, the aim of this in vitro study was to evaluate the effects of placing short posts made of different restorative materials in primary maxillary incisors on the fracture resistance of root canals of primary teeth. The null hypothesis was that there was no difference between the fracture load of primary maxillary incisor root canals reinforced using short posts made of different restorative materials.

\section{Methods}

\section{Specimen Preparation}

The study was approved by the Ethics Committee of King Saud University, College of Dentistry (FR 0331). Forty extracted human primary maxillary incisor teeth taken from patients who consented for their teeth to be used for research purposes with at least two-thirds of the root was intact, were collected and stored in $0.1 \%$ thymol and used in this study if the mean root canal length of primary anterior teeth using the direct visual method was reported as $14.58 \mathrm{~mm}$ and they met the other inclusion criteria. The teeth were radiographed from the proximal view to ensure that they did not receive any pulp therapy and that there was no evidence of calcification or pathologic resorption. In addition, the cervical third of the crowns should have been intact, and no pathologic resorption of the root should have been evident. The roots of the extracted teeth were sectioned $1 \mathrm{~mm}$ above the cementoenamel junction (CEJ) using low-speed carborundum discs [3 M ESPE Dental Products, St. Paul, MN, USA] under water spray. The obtained roots were standardized to a length of $10 \mathrm{~mm}$.

\section{Root Canal Procedures}

A single operator instrumented and performed the standard root canal procedures for all the specimens. The working length was measured by deducting $1 \mathrm{~mm}$ from the lengths recorded when the tip of a \#25K-file was visible at the apical end. The canals were enlarged coronally with size 2 and 3 Gates-Glidden burs [Sendoline Perfect Endo, Täby, Sweden]. A standard root canal procedure was performed using K3 Ni-Ti rotary instruments [SybronEndo, Glendora, CA, USA] according to the manufacturer's instructions until a \#40/0.06 file reached the working length. The canals were irrigated with $2 \mathrm{~mL}$ of $1.3 \%$ $\mathrm{NaOCl}$ at each change of instrument. Irrigation was carried out with a 27-G side-vented needle [Monoject; Covidien LP, Deland, FL, USA] attached to a 5-mL syringe inserted at a distance of $2 \mathrm{~mm}$ from the working length without binding. To simulate the clinical challenges, a closed system was created by closing the apex of each root with a resin composite. After cleaning, shaping and drying of the root canal with absorbent paper points, each canal was obturated with Vitapex [Neo Dental International Inc. Federal Way, WA, USA] and then randomly divided into five groups of 8 each [Groups 1-5]. At the level of significance $\sigma=0.05$ with estimated standard deviation $=0.85$ and power $=82$, the sample size should be at least 8 in each group. The teeth were wrapped in wet gauzes and stored at room temperature for 72 hours until use.

\section{Post Space Procedures}

The Vitapex [4 mm] was removed from each canal to create a post space in Groups 1-4, while Group 5 was kept as a control. Group 1 was filled with bulk-fill resin composite [Tetric ${ }^{\circledR}$ N-Ceram Bulk Fill - Ivoclar Vivadent, Buffalo, NY, USA], Group 2 was filled with flowable resin composite [AeliteFlo - BISCO, Inc., Anaheim, CA], Group 3 was filled with nanohybrid universal resin composite [Filtek Z250 XT 3 M ESPE Dental Products, St. Paul, MN, USA], and Group 4 was filled with resin-modified glass ionomer [GC Fuji II LC $^{\circledR}$ capsule - GC America Inc., Alsip, IL, USA]. Each material was used according to the manufacturers' instructions. The teeth from all groups were stored in deionized water in a sealed container for 48 hours at room temperature before thermocycling. All specimens were placed for thermocycling [SD Mechatronik GmbH Dental Research Equipment, W. Germany] between $5^{\circ} \mathrm{C}$ and $55^{\circ} \mathrm{C}$ with a dwell time of 30 seconds and a transfer time of 5 seconds for 1500 cycles.

\section{Measurement of Fracture Resistance}

All specimens were mounted vertically in autopolymerizing acrylic resin [Ortho-Jet, Lang Dental MFG, IL, USA] within a cylindrical mold in a way that the coronal tooth portion protruded $5 \mathrm{~mm}$ out of the ortho resin. Fracture 
resistance was measured using a universal testing machine [Model No. 8500, Instron, Canton, MA, USA] at a $0.5-\mathrm{mm} / \mathrm{min}$ crosshead speed using a ball-ended cylindrical tip $4 \mathrm{~mm}$ in diameter. The tip was loaded at the center of each restoration parallel to the vertical axis of the tooth. The ultimate load at fracture was recorded in Newtons [N].

\section{Statistical Analysis}

The level of significance was set at $\alpha=0.05$, and any test with a $\mathrm{P}$ value less than that was considered significant. The Shapiro-Wilk test was used to test the assumption of normality within each group, and normality satisfied $\mathrm{P}>0.05$. One-way analysis of variance (ANOVA) was used to compare the groups based on their means, and if ANOVA showed a significant difference among the group means ( $\mathrm{P}<0.05)$, then Tukey's pairwise multiple comparison test was used. The statistical analysis was carried out with SPSS version 25.0 [Statistical Package for the Social Sciences, SPSS, Chicago, Illinois, USA].

\section{Results}

The mean fracture force and SD as well as the $95 \%$ confidence interval for the mean of each material were as follows: Tetric ${ }^{\circledR}$ N-Ceram Bulk Fill 239.91 \pm 93.57 (161.68, 118.14), AeliteFlo $375.74 \pm 19.73$ (359.25, 392.23), Filtek Z250 XT 318.78 \pm 12.84 (308.04, 329.51), GC Fuji II LC ${ }^{\circledR}$ capsule 439.82 \pm 25.16 (418.79, 460.85) and Control 423.37 \pm 178.71 (258.09. 588.65) (Table 1 and Figure 1). The multiple comparison test showed that the Tetric ${ }^{\circledR}$ N-Ceram Bulk Fill significantly $(\mathrm{P}<0.05)$ had the lowest mean compared with the other materials except for Filtek Z250 XT, whose mean was lower but not significant $(\mathrm{P}=0.390)$. Furthermore, multiple comparison tests showed that there was no significant difference in averages among Filtek Z250 XT, AeliteFlo, Control and GC Fuji II LC ${ }^{\circledR}$ capsules $(\mathrm{P}>0.05)$ (Table 2). The highest fracture resistance was recorded for GC Fuji II LC capsules [439.82 N] and control [423.37 N], while the lowest fracture resistance was recorded for Tetric ${ }^{\circledR} \mathrm{N}$ Ceram Bulk Fill [239.91 N].

\section{Discussion}

The null hypothesis was rejected, as there was a difference between the fracture load of primary maxillary incisor teeth restored using short posts made of different restorative materials. Fracture resistance is one of the main desirable characteristics of restoration materials, especially during mastication, and the most important factor in achieving a durable restoration. ${ }^{20} \mathrm{~A}$ study reported that the maximum bite force in 3- to 6-year-old children, measured at the first and second molars and central incisors, ranged from 12.61 to 353.6 $\mathrm{N}($ mean $=196.6 \mathrm{~N}){ }^{21}$ Another study reported this value as $176 \mathrm{~N}$ in the early primary stage and $240 \mathrm{~N}$ in the late primary stage. $^{22}$ It should be noted that these forces are considerably greater in the oral environment under physiological conditions and affect the materials used through constant stresses. ${ }^{23}$ With this introduction, since, in our study, the mean fracture resistance values varied from $239.91 \mathrm{~N}$ to $439.82 \mathrm{~N}$, it can be predicted that all groups in this study are clinically acceptable, particularly AeliteFlo (375.74 N), Control (423.37 N), and GC Fuji II LC ${ }^{\circledR}$ capsule (439.82 N), whose mean biting forces are higher than the reported highest mean biting forces of 196.6 $\mathrm{N}$ and $176 \mathrm{~N} .^{21,22}$

Endodontic treatment and the application of intracanal reinforcements might be necessary before building the crown in primary incisors with extensive coronal destruction to increase the bonding surface area and thus increase restoration resistance to masticatory forces. ${ }^{24}$ Therefore, applying reinforcement in the coronal third of the root canal $3 \mathrm{~mm}$ under the CEJ may be required. ${ }^{2,25}$ In the present study, $4 \mathrm{~mm}$ of the Vitapex was removed from each canal to create a post space in Groups $1-4$, but the roots of the extracted teeth were sectioned $1 \mathrm{~mm}$ above the CEJ, which was only $3 \mathrm{~mm}$ under the CEJ similar to other studies. ${ }^{1,15,26}$ Post placement has a significant influence on the final fracture resistance of the restored tooth. ${ }^{27}$

Table I Comparing All Groups Average Fracture Resistance Using One Way Analysis of Variance

\begin{tabular}{|c|c|c|c|c|c|}
\hline \multirow[t]{2}{*}{ Groups } & \multirow[t]{2}{*}{$\operatorname{Mean}[\mathbf{N}]$} & \multirow[t]{2}{*}{ Std. Deviation } & \multirow[t]{2}{*}{ ANOVA P-value } & \multicolumn{2}{|c|}{ 95\% Confidence Interval for Mean } \\
\hline & & & & Lower Bound & Upper Bound \\
\hline Tetric $^{\circledR}$ N-Ceram Bulk Fill & 239.91 & 93.57 & $0.000 I^{*}$ & 161.68 & 318.14 \\
\hline AeliteFlo & 375.74 & 19.73 & & 359.25 & 392.23 \\
\hline Filtek Z250 XT & 318.78 & 12.84 & & 308.04 & 329.51 \\
\hline GC Fuji II LC ${ }^{\circledR}$ Capsule & 439.82 & 25.16 & & 418.79 & 460.85 \\
\hline Control & 423.37 & $|78.7|$ & & 258.09 & 588.65 \\
\hline
\end{tabular}

Note: *Indicates statistical significance. 


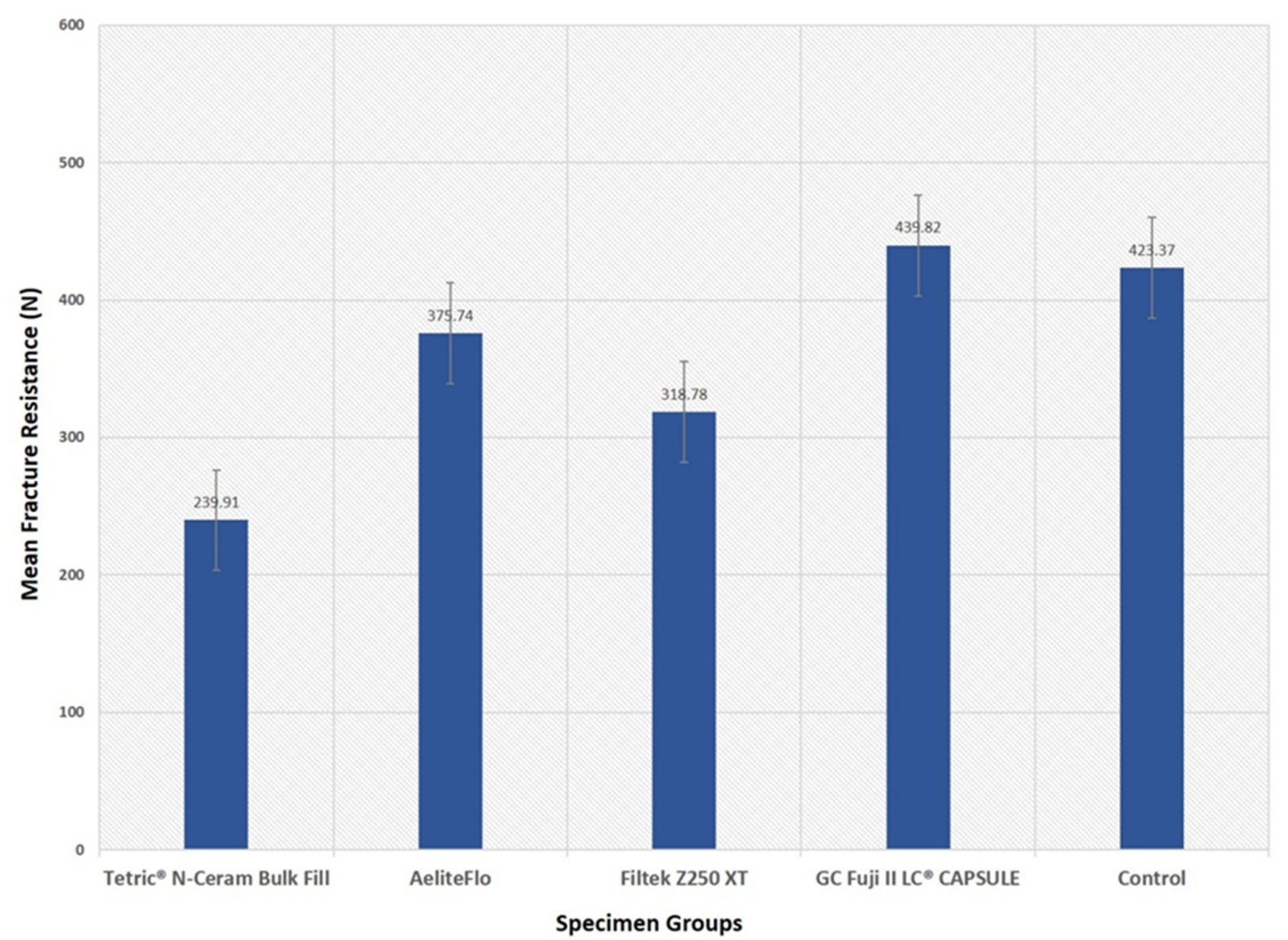

Figure I Comparing the groups by their mean fracture resistance.

Unfortunately, there is a scarcity of studies measuring the fracture resistance of posts in primary teeth, which creates some limitations in comparing the results of our study with others. A study reported that the fracture resistance of resin composite posts, which included crown restoration and force applied at $148^{\circ}$ along the long axis of the primary incisors on the mid-palatal surface, was $278.70 ~ N .^{26}$ In addition, their methodology was different than the one used in our study, as they used 1-mm light-cured Dycal Lime-Lite under the post, and the post was covered with a 4-mm resin composite crown. ${ }^{26}$ Another study tested the fracture resistance of resin composite posts, which included crown restoration, and it was $268.194 \mathrm{~N}^{7}$ In contrast, in our study, we did not use a liner or cover the post with a crown, and force was applied parallel to the long axis of the tooth. Fracture resistance for Filtek Z250 XT was $318.78 \mathrm{~N}$; for AeliteFlo it was $375.74 \mathrm{~N}$ and for Tetric $^{\circledR}$ N-Ceram Bulk Fill it was 239.91 N. In our study, the force was applied parallel to the long axis of the tooth, as no

Table 2 Multiple Comparison Test Comparing Pairwise Groups Average Fracture Resistance

\begin{tabular}{|l|c|c|c|c|c|}
\hline \multirow{2}{*}{ Groups } & \multicolumn{4}{|c|}{ Multiple Comparison Test* } \\
\cline { 2 - 6 } & Tetric $^{\circledR}$ N-Ceram Bulk Fill & AeliteFlo & Filtek Z250 XT & GC Fuji II LC ${ }^{\circledR}$ Capsule & \multicolumn{1}{|c|}{ Control } \\
\hline Tetric $^{\circledR}$ N-Ceram Bulk Fill & $\mathrm{I}$ & & & \\
AeliteFlo & 0.030 & $\mathrm{I}$ & & & \\
Filtek Z250 XT & 0.390 & 0.693 & $\mathrm{I}$ & $\mathrm{I}$ \\
GC Fuji II LC ${ }^{\circledR}$ Capsule & 0.001 & 0.593 & 0.065 & 0.996 & $\mathrm{I}$ \\
Control & 0.002 & 0.830 & 0.168 & & \\
\hline
\end{tabular}

Note: *Tukey's test. 
crown was constructed after the post. Many studies have reported that applying the force vertically to the long axis of the tooth transmits the force uniformly. In our study, each specimen was embedded vertically in an acrylic resin block, leaving the coronal part unimpeded. This design is more relevant clinically, as it efficiently simulates the support given to healthy teeth by alveolar bone and results in less catastrophic stress build-ups caused by unrealistic bending movements. Other studies used different loading angles on the restored crown, including alignment at a $45^{\circ}$ angle to the tooth's long axis. $^{28,29}$ The loading angle of teeth with post restorations can strongly affect fracture resistance, and the mean failure loads increase as the loading angle approaches an orientation parallel to the long axes of the teeth. ${ }^{28,29}$ In our study, the loading angle was parallel to the long axes of the teeth, which were kept moist throughout the experiment, since drying can adversely affect bonding to dentin.

The ideal properties of the post and core indicate that it should be resorbable, but it should provide adequate retention and resistance, and the post should be well adapted to the inner dentinal wall, as it is one of the governing factors for the retention of the restoration. ${ }^{18}$ In our study, we followed the manufacturers' instructions for all postrestorative materials, which could help in adapting the materials to the inner dentinal wall, leaving only $3 \mathrm{~mm}$ of the post under the CEJ to avoid interference with root resorption. Other much-needed requirements of intracanal posts for primary anterior teeth are biocompatibility, availability, ease of application, esthetics, and ability to withstand masticatory forces. ${ }^{17}$ The materials used in our study were available, easily applied, and mostly had high fracture resistance.

The use of intracanal posts in endodontically treated teeth offers an esthetic and functional treatment option for severely decayed primary anterior teeth. ${ }^{3}$ In our study, the mean fracture resistance values varied from $239.91 \mathrm{~N}$ to $439.82 \mathrm{~N}$. This may be due to the different compositions of the materials. The highest fracture resistance was observed with the GC Fuji II LC ${ }^{\circledR}$ capsule, followed by the control. The high fracture resistance of the control, which was Vitapex, may be due to continuation of the same material inside the root canal.

For primary teeth, no consensus exists concerning the proper length of posts, and the influence of long posts on primary teeth needs to be determined. Accordingly, a study investigated the effect of increasing the length of the posts on the strength of pulp-treated primary anterior teeth by evaluating the fracture resistance of primary anterior teeth restored with long dentin posts that would undergo natural resorption in comparison to primary anterior teeth restored with short fiber posts. ${ }^{4}$ The forementioned study concluded that short fiber posts offered better fracture resistance than long dentin posts. ${ }^{4}$ In our study, we used different restorative materials, as their techniques are simple to apply. Similar to our study, the use of resin composites was reported in other studies. ${ }^{9,10}$ Regarding resin composite posts, there is a risk of a loss of retention owing to polymerization shrinkage. ${ }^{10}$

The limitations of this study may include the smaller sample size, which was due to the difficulty in collecting primary anterior teeth with at least two-thirds of the root present. In addition, it is difficult to replicate intraoral conditions during in vitro studies; however, we performed thermocycling of specimens to simulate oral clinical conditions to some extent. The effect of the periodontium was not reproduced in this study, and all roots were embedded directly in acrylic blocks.

Covering roots with silicon or wax before embedding them in acrylic resin may cause root movement during loading, which may not allow the study of the actual behavior of the restorative technique used. Furthermore, such periodontal membrane simulating materials have different elasticities than that of the periodontium and thus are not representative of the clinical status. Another limitation is that no attempt to determine the failure mode was considered, and further investigations may consider restoration of the crown.

\section{Conclusion}

Within the limitations of this study, the following conclusions can be stated:

1. The fracture resistance of primary incisors differs depending on the material used as intracanal posts.

2. The mean fracture resistance for all groups is clinically acceptable and higher than the highest mean biting force for children reported in the literature.

3. Three-millimeter intracanal posts in the primary incisors showed the highest fracture resistance for the teeth restored with GC Fuji II LC capsules and the control.

4. The Tetric ${ }^{\circledR}$ N-Ceram Bulk Fill intracranal posts resulted in significantly lower mean fracture resistance than the other posts.

5. The fracture resistances of the control and GC Fuji II LC ${ }^{\circledR}$ capsule groups were similar.

\section{Disclosure}

The authors report no conflicts of interest in this work. 


\section{References}

1. Vieira CL, Ribeiro CC. Polyethylene fiber tape used as a post and core in decayed primary anterior teeth: a treatment option. $J$ Clin Pediatr Dent. 2001;26:1-4.

2. Sharaf AA. The application of fiber core posts in restoring badly destroyed primary incisors. J Clin Pediatr Dent. 2002;26:217-224. doi:10.17796/jcpd.26.3.y3660x50n510jv0p

3. Gujjar KR, Indushekar KR. Comparison of the retentive strength of 3 different posts in restoring badly broken primary maxillary incisors. $J$ Dent Child. 2010;77:17-24.

4. Ghazawy R, Badran A. Comparative evaluation of fracture resistance of primary anterior teeth restored with long dentine posts and teeth restored with short fiber posts: an in vitro study. Future Dental $J$. 2018;4:54-58. doi:10.1016/j.fdj.2017.11.003

5. Mortada A, King NM. A simplified technique for the restoration of severely mutilated primary anterior teeth. $J$ Clin Pediatr Dent. 2004;28:187-192. doi:10.17796/jcpd.28.3.2554xv412644ru13

6. Pinheiro SL, Bönecker MJ, Duarte DA, et al. Bond strength analysis of intracanal posts used in anterior primary teeth: an in vitro study. $J$ Clin Pediatr Dent. 2006;31:32-34. doi:10.17796/jcpd.31.1.547tqq657 4361549

7. Baghalian A, Ranjpour M, Hooshmand T, et al. Comparison of fracture resistance in post restorations in primary maxillary incisors. Eur J Paediatr Dent. 2014;15:313-316.

8. Wanderley MT, Ferreira SL, Rodrigues CR, et al. Primary anterior tooth restoration using posts with macroretentive elements. Quintessence Int. 1999;30:432-436.

9. Mendes FM, De Benedetto MS, Del Conte Zardetto CG, et al. Resin composite restoration in primary anterior teeth using short post technique and strip crowns: a case report. Quintessence Int. 2004;35:689-692.

10. Judd PL, Kenny DJ, Johnston DH, et al. Composite resin short-post technique for primary anterior teeth. $J$ Am Dent Assoc. 1990;120:553-555. doi:10.14219/jada.archive.1990.0071

11. Ramires-Romito AC, Wanderley MT, Oliveira MD, et al. Biologic restoration of primary anterior teeth. Quintessence Int. 2000;31:405-411.

12. Grewal N, Seth R. Comparative in vivo evaluation of restoring severely mutilated primary anterior teeth with biological post and crown preparation and reinforced composite restoration. J Indian Soc Pedod Prev Dent. 2008;26:141-148. doi:10.4103/0970-4388.44028

13. Eshghi A, Esfahan RK, Khoroushi M. A simple method for reconstruction of severely damaged primary anterior teeth. Dent Res J. 2011;8:221-225. doi:10.4103/1735-3327.86046

14. Mizutani T, Nakayama A, Iwasaki H, et al. Suitability of polymers as screw post materials in primary teeth: an in vitro study. Eur J Paediatr Dent. 2012;13:19-24.
15. Verma L, Passi S. Glass fibre-reinforced composite post and core used in decayed primary anterior teeth: a case report. Case Rep Dent. 2011;864254:1-4. doi:10.1155/2011/864254

16. Mehra M, Grover R. Glass fiber post: an alternative for restoring grossly decayed primary incisors. Int $J$ Clin Pediatr Dent. 2012;5:159-162.

17. Mittal N, Bhatia HP, Haider K. Methods of intracanal reinforcement in primary anterior teeth- assessing the outcomes through a systematic literature review. Int $J$ Clin Pediatr Dent. 2015;8:48-54. doi:10.5005/jp-journals-10005-1282

18. Shah S, Bargale S, Anuradha KVR, et al. Posts in primary teeth a sile for better smile. J Adv Med Dent Sci Res. 2016;4:58-64.

19. Papathanasiou AG, Curzon ME, Fairpo CG. The influence of restorative material on the survival rate of the restorations in primary molars. Pediatr Dent. 1994;16:282-288.

20. Samaha AE, EL-Shabrawy S, EL-Meligy O, Hashem R. Clinical and laboratory evaluation of two different types of the post system in restoring destructed primary anterior teeth. Egypt Dent J. 2005;51:1159-1177.

21. Mountain G, Wood D, Toumba J. Bite force measurement in children with primary dentition. Int J Paediatr Dent. 2011;21:112-118. doi:10.1111/j.1365-263X.2010.01098.x

22. Owais AI, Shaweesh M, Abu Alhaija ES. Maximum occusal bite force for children in different dentition stages. Eur $J$ Orthod. 2013;35:427-433. doi:10.1093/ejo/cjs021

23. Makade CS, Meshram GK, Warhadpande M, et al. A comparative evaluation of fracture resistance of endodontically treated teeth restored with different post core systems - an in-vitro study. $J A d v$ Prosthodont. 2011;3:90-95. doi:10.4047/jap.2011.3.2.90

24. Eshghi A, Kowsari-Isfahan R, Khoroushi M. Evaluation of three restorative techniques for primary anterior teeth with extensive carious lesions: a 1-year clinical study. J Dent Child. 2013;2:80-87.

25. Babaji P, Chaurasia V, Chaurasia R, et al. Restoration of destructed primary teeth with post and core. In: Textbook of Crowns in Pediatric Dentistry. 1st. Jaypee; 2015:125-132.

26. Seraj B, Ghadimi S, Estaki Z, et al. Fracture resistance of three different posts in restoration of severely damaged primary anterior teeth: an in-vitro study. Dent Res J. 2015;12:372-378. doi:10.4103/ 1735-3327.161461

27. Mangold JT, Kern M. Influence of glass-fiber posts on the fracture resistance and failure pattern of endodontically treated premolars with varying substance loss: an in vitro study. $J$ Prosthet Dent. 2011;105:387-393. doi:10.1016/S0022-3913(11)60080-2

28. Loney RW, Moulding MB, Ritsco RG. The effect of load angulation on fracture resistance of teeth restored with cast post and cores and crowns. Int J Prosthodont. 1995;8:247-251.

29. Hayashi M, Takahashi Y, Imazato S, et al. Fracture resistance of pulpless teeth restored with post-cores and crowns. Dent Mater. 2006;22:477-485. doi:10.1016/j.dental.2005.03.017

\section{Publish your work in this journal}

Clinical, Cosmetic and Investigational Dentistry is an international, peer-reviewed, open access, online journal focusing on the latest clinical and experimental research in dentistry with specific emphasis on cosmetic interventions. Innovative developments in dental materials, techniques and devices that improve outcomes and patient satisfaction and preference will be highlighted. The manuscript management system is completely online and includes a very quick and fair peer-review system, which is all easy to use. Visit http://www.dovepress.com/testimonials.php to read real quotes from published authors. 